\title{
A Scalable Digital Infrastructure for Sustainable Energy Grid Enabled by Distributed Ledger Technology
}

\author{
Rahim Rahmani ${ }^{a *}$, Yuhong $\mathrm{Li}^{b}$ \\ ${ }^{a}$ Department of Computer and System Sciences, University of Stockholm, Sweden \\ ${ }^{b}$ Beijing University of Posts and Telecommunications, Beijing, China
}

\begin{abstract}
The future of renewable energy transportation and distribution is dynamic and complex, with distributed renewable resources in required distributed control. It is suggested that Distributed Ledger Technology (DLT) is a timely innovation with the potential to facilitate this future. The transition to full renewable energy requires an infrastructure capable of handling intermittent production that has a low marginal cost. This requires a distributed control logic where devices with embedded intelligence coordinate local production, a decentralized energy market where prices are not primarily based on production, and an underlying digital infrastructure to enable both. Simulations and experiments have demonstrated great potential in such a digital infrastructure, but real-life tests have identified scalability as a remaining challenge. In this paper, we propose a DLT-based architecture for the energy grid with the development of existing solution concepts by implementing scalability solutions. To this end, we derive energy market components as a framework for building efficient microgrid. Then, we discuss the microgrid as a case study of such a market according to the required components within energy production, transmission, and distribution; distributed ledger platform operations, IoT device manufacturing,; software development; and research in IoT, edge and cloud computing, and energy systems.
\end{abstract}

Keywords: Blockchain, Smart Grid, Scalable Distributed Ledger Technology, Microgrid, Peer-to-peer; Renewable energy, IoT, Edge computing

\section{Introduction}

Significant energy grid infrastructure changes are currently being implemented in the systems globally by maximizing the penetration of renewable energy, installing new transmission lines, adding flexible loads and promoting new changing in disintegrating the grid into microgrids [1 ].

The changing nature of grid operations, the increasing penetration of Distributed Energy Renewables (DER), and the introduction of other new technologies are putting pressure on existing energy systems. But the transition toward an energy system that can handle high levels of DER production is not straightforward. Growing levels of DER production means increasing reliance on an energy system where production is non-inertial, is highly variable, is intermittent, and has a low marginal costs. Consequently, increasing penetration of DERs make grid operations difficult with centralized control and it challenges existing energy pricing and valuation models [1]. What is needed is a new infrastructure capable of meeting the requirements of future energy systems. Many components of such a new infrastructure already exist. For instance, metering and control systems with embedded intelligence make it possible to distribute the data analytics required for scheduling and for creating markets for local energy trading. Relatedly, recent developments in distributed and decentralized computing make it possible to create a digital infrastructure for the required records keeping and execution of logic. Put differently, novel digital infrastructures can both enable DER growth and connect existing transmission networks with DERs to supply load centers with low-carbon power that, when combined with energy storage solutions, increase resilience and provides operational flexibility. These possibilities have not gone unnoticed. The use of local microgrid renewable energy can contribute to the environment sustainability and socioeconomic growth [2]. Microgrid represents in general an efficient power distribution and transmission system by making use effectively the existing power infrastructure. Microgrids have been proven to be able to reduce costs concerning generation, outages, operational costs for transmission and distribution, and mitigate carbon dioxide (CO2) emissions [3].

However, the energy system of the future will be decentralized and based on renewable energies. This puts forward new challenges in stabilizing the energy transmission and distribution system and satisfying the needs of users.

- As more and more energies are produced by households or small, private companies, both the energy distribution networks and the big, central energy producing plants are to be affected. How to maintain and optimize the grid stability is a big challenge to grid operators.

- Since customers are deeply involved in the energy system, new mechanism and models needs to be

${ }^{*}$ Corresponding author. Tel.: +46- 8-6747494; E-mail:

rahim@dsv.su.se

(C) 2020 International Association for Sharing Knowledge and Sustainability.

DOI: $10.5383 / J U S P N .12 .02 .003$ 
introduced to operate the grid in order to reduce the energy waste.

- New demands from energy consumers will emerge. For example, consumers may also want to use the green energy and be sure what energy they are using. How to keep the energy system transparent to the customers is of great importance.

Distributed Ledger Technology (DLT), providing distributed trust, anonymity, data integrity and availability [4][5]. DLT can benefit the energy system in two aspects fundamentally. One is it is distributed system in nature. The other is DLT has intrinsic security mechanisms by design. Hence, DLT can be a promising technology for meeting the requirements of future energy system. Decentralized energy system consist of smallscale energy generators that are placed in same location with an energy consumption point which called micro grid. Microgrids can aid in ensuring the reliable an efficient power distribution and transmission system. Microgrids in large scale can reduce the need for expansive inefficient energy transportation with substantial losses [6].

Therefore, we focus on a scalable DLT-based solution design specifically as a key technology that manages and controls nods in microgrids applications which are mainly focused on payments and on record keeping. This allows microgrids node applications and edge computing systems to operate at any points and the energy grid application will be able to incorporate microgrids heterogeneous context entities in heterogeneous domain, this heterogeneity mandates to look into interoperability reasoning approaches.

The concept allows microgrids gateways to collect and process interoperability of data from devices easily. To achieve this, we propose new strategies that make our solution more scalable. The contribution of this paper can be summarized as follows. We present the design and implementation details of our proposed DLT-based microgrid gateway solution support scalability. The solution support management and data Interoperability with other cloud-based solutions. The architecture is scalable and promotes ease-of-use.

The rest of the paper is structured as follows. Section 2 defines the motivation and related works of DLT-based microgrid gateway and Section 3 describes the conceptual model of the framework; Section 4 presents the performance evaluation and the conclusions are provided in section 5

\section{Motivation and Related Works}

In this section we briefly discuss the related works and our motivation behind this work

\subsection{DLT-based MicroGrids}

Sustainability and an efficient use of microgrid renewable resources are inherently linked to taking advantage of DLT which strengthen the local community in terms of selfsufficiency and provide the possibility of energy cost reduction. An important objective of using DLT-based microgrid is to promote the use of renewable energy sources within the energy grid.

A distributed ledger is a database that is shared and synchronized across microgrid network nodes consensually. Participants at each node of the microgird network can access the recordings shared across the nodes in the network and can own an identical copy of them. By making the recordings public witness, no single participant can alter or reverse the data in the record, unless the change is agreed by all participants in the network in a subsequent transaction Through this way, DLT provides certain level of security guarantees to the data recorded in the ledger. Therefore, DLT is being used in different areas, such as intelligent transportation, Industry 4.0, healthcare smart grid and supply chain management, etc. Work in [7] proposed a blockchain (is a DLT) ecosystem model for electric vehicle and charging pile management, which uses elliptic curve cryptography to calculate hash functions of electric vehicles and charging piles. In [8], the function of the smart contract is to identify malicious usage of electrical power. Consumer data being manipulated maliciously on the smart grid network will trigger the smart contract to send an encrypted message to the smart meter and displayed on the screen of the smart meter of the consumer. Different from this work, we use the intrinsic mechanism of blockchain to provide security and transparency to users; in addition, we concentrate on analyzing work for solving the scalability issue raised by integrating DLT with microgrids and work regarding cloud and fog computing which are closely related with the mechanism proposed in the paper.

\subsection{Scalability for DLT Integrating with MicroGrid}

The extant literature offers poor guidance as technical details are scant and most projects and academic papers suffer from inflated expectations. Such unsubstantiated claims result from a combination of poor technical understanding, a misrepresentation of facts, a lack of critical scrutiny [9],[10] and [2] and biased authors with large personal stakes [11]. This is evidenced by the numerous technical challenges that have derailed real world implementation trials like DAISEE, Alliander Alva [7], and the AGL trials [12]. Therefore, we base our design on the analytical framework. Three aspects are considered: (1) the configuration of the technical components, (2) the characteristics of the value exchange network, and (3) the energy application domain.

The first aspect lists the technology categories and solution types that are used to design a blockchain/DLT/DDBMS as shown in [13] and Table 1 for a description of each solution type together with its general advantages and disadvantages. Every blockchain/DLT/DDBMS is a configuration of solution types and these configurations fall into three groups: (1) Distributed and Centralized Elective, (2) Distributed and Decentralized Elective, or (3) Distributed and Decentralized. An example of (1) is Hyperledger Fabric [14] (configured as $\{\mathrm{N} 2 / 3, \mathrm{D} 2, \mathrm{C} 2, \mathrm{~A} 4 / 5, \mathrm{I} 2, \mathrm{U} 2\}$ in Table 1). Its parametrization optimizes for low latency finality and high transaction throughput, but suffers from centralization $(<20$ nodes $)$ and requires trusted actors. Examples of (2) are NEO and systems that run ALGORAND [15] (configured as $\{\mathrm{N} 1, \mathrm{C} 3, \mathrm{I} 1, \mathrm{U} 2\}$ with $\mathrm{xBFT}$ when favoring transaction throughput and $\mathrm{d} / \mathrm{fPoW} / \mathrm{S}$ when favoring security and node counts). The parametrization optimizes for low latency finality and a balance between node count and transaction throughput, but has lower security and the validator set can collude. An example of (3) is Ethereum [16] (configured as \{N1, D1, C1, A1, I1, U1 \}). Its parametrization optimizes for a large node counts, security, and robustness [17], but sacrifices transaction throughput and low latency absolute finality.

The second aspect is the characteristics of the value exchanges as shown in Table 2. The configuration of technical components must fit the characteristics of the value exchange network, 
Table 1. Technology categories and solution types with details of suitable and non-suitable use [13].

\begin{tabular}{|c|c|c|c|c|}
\hline Category & $\begin{array}{l}\text { Solution } \\
\text { Type }\end{array}$ & Description & Advantages & Disadvantages \\
\hline \multirow[t]{3}{*}{$\begin{array}{l}\text { Network } \\
\text { Mgmt. }\end{array}$} & Public & Opt-in and self-generated membership & $\begin{array}{l}\text { Decentralization Inclusive, } \\
\text { Censorship Resistance }\end{array}$ & $\begin{array}{l}\text { Computation bound, High latency, No } \\
\text { absolute finality. Throughput, Legal } \\
\text { issues }\end{array}$ \\
\hline & Consortium & $\begin{array}{l}\text { Access and membership is controlled by a set of } \\
\text { actors }\end{array}$ & $\begin{array}{l}\text { Low Latency, Absolut finality, } \\
\text { Throughput Legal compliance }\end{array}$ & $\begin{array}{l}\text { Centralized, less inclusive, } \\
\text { censorable, Requires membership } \\
\text { management }\end{array}$ \\
\hline & Private & $\begin{array}{l}\text { Access and membership is controlled by a single } \\
\text { actor }\end{array}$ & $\begin{array}{l}\text { Same as consortium but cheaper, } \\
\text { scalable and easier to control }\end{array}$ & Same as consortium but less secure \\
\hline \multirow[t]{2}{*}{$\begin{array}{l}\text { Data } \\
\text { Mgmt. }\end{array}$} & On-chain & Valid tx do not link to external data & $\begin{array}{l}\text { Transparency, Auditability, Data } \\
\text { availability, }\end{array}$ & Efficient storage scaling Legal issues \\
\hline & Off-chain & $\begin{array}{l}\text { Valid tx contain hash-pointers to externally stored } \\
\text { data }\end{array}$ & $\begin{array}{l}\text { Efficient storage, scaling, } \\
\text { Regulatory compliance }\end{array}$ & $\begin{array}{l}\text { Added database operations and } \\
\text { maintenance needs }\end{array}$ \\
\hline \multirow{3}{*}{$\begin{array}{l}\text { Commit } \\
\text { Right }\end{array}$} & Randomized & Randomly assigned commit right & Depends on consensus Algorithm & Depends on consensus algorithm \\
\hline & Elective & Certain actors have commit right & Greatro control & Not for public, Same as Randomized \\
\hline & Hybrid & Elected set of actors randomize cach commit right & Same as randomized & Not for private, same as randomized \\
\hline \multirow[t]{5}{*}{$\begin{array}{l}\text { Consensus } \\
\text { Algorithm }\end{array}$} & PoW & $\begin{array}{l}\text { Computation increases probability of attaining a } \\
\text { commit right }\end{array}$ & $\begin{array}{l}\text { Objectively verifiable, Sybil attack } \\
\text { resistant }\end{array}$ & $\begin{array}{l}\text { Energy requirements. If randomized } \\
\text { then limited to probabilistic finality }\end{array}$ \\
\hline & $\mathrm{PoS}$ & $\begin{array}{l}\text { Size of stake increased probability of attaining a } \\
\text { commit right }\end{array}$ & Energy efficient & $\begin{array}{l}\text { Human input is required to determine } \\
\text { slashing }\end{array}$ \\
\hline & $\mathrm{d} / \mathrm{fPoW} / \mathrm{S}$ & $\begin{array}{l}\text { Actors vote for a validator set who in turn rely on } \\
\text { Pow/S }\end{array}$ & $\begin{array}{l}\text { Energy efficient. Can offer absolute } \\
\text { finality }\end{array}$ & $\begin{array}{l}\text { Sacrifices collusion resistance. Easier } \\
\text { to manipulate }\end{array}$ \\
\hline & $\mathrm{xBFT}$ & $\begin{array}{l}\text { Voting schemes that are based on BFT algorithms } \\
\text { and their variants }\end{array}$ & $\begin{array}{l}\text { Time tested. Energy efficient with } \\
\text { absolute finality }\end{array}$ & $\begin{array}{l}\text { Communication bound Dynamic } \\
\text { validator sets can be problematic }\end{array}$ \\
\hline & CFT & $\begin{array}{l}\text { Voting schemes that are based around trusted } \\
\text { nodes (Leader-follower) }\end{array}$ & $\begin{array}{l}\text { Same as XBFT but not bound by } \\
\text { message exchange }\end{array}$ & Cannot handle Byzantine agent \\
\hline \multirow[t]{2}{*}{$\begin{array}{l}\text { Identity } \\
\text { Mgmt }\end{array}$} & $\begin{array}{l}\text { Self- } \\
\text { sovereign } \\
\text { identity }\end{array}$ & $\begin{array}{l}\text { Nodes own and control their identity without } \\
\text { disclosing personal data }\end{array}$ & Control over data, Privacy & Difficult for users to use \\
\hline & $\begin{array}{l}\text { Decentralized } \\
\text { Trust identity }\end{array}$ & $\begin{array}{l}\text { A central server identity proofs nodes who then } \\
\text { can manage their own keys }\end{array}$ & $\begin{array}{l}\text { Easy to use in a trusted network. } \\
\text { Legal compliance }\end{array}$ & Is not private \\
\hline \multirow[t]{2}{*}{ Automation } & $\begin{array}{l}\text { Deterministic } \\
\text { instruction } \\
\text { sets }\end{array}$ & $\begin{array}{l}\text { Nodes can independently verify the output of a } \\
\text { method input }\end{array}$ & $\begin{array}{l}\text { Does not require message } \\
\text { exchanges }\end{array}$ & Poor Programming language support \\
\hline & $\begin{array}{l}\text { Non- } \\
\text { deterministic }\end{array}$ & $\begin{array}{l}\text { Simulate and compare schemes where nodes } \\
\text { compare execution results prior to a commit }\end{array}$ & $\begin{array}{l}\text { Consortium and private networks, } \\
\text { Works with most programming } \\
\text { language }\end{array}$ & Does not support pblic \\
\hline
\end{tabular}

which can be classified as either: (i) Digitized Assurance Based, (ii) Digitalized Evidence Based, or (iii) Digitalized Selfcontained. Enterprise solutions are often configured as (i) and involve exchanges between trusted actors governed by legal contracts. This archetype is most suitable for the Distributed and Centralized Elective technical configuration. An example of (ii) is the Etherisc.com project. Here, value exchanges rely on provable statements from a quorum of independent actors. This archetype leverages the technical capabilities of more recently developed value exchange networks but suffer from data input problems. The configuration is \{digital only / cyberphysical (in) distinguishable, objective exchange / randomized quorum $\}$ and the archetype is most suitable for the Distributed and Decentralized Elective technical configuration. The third, i.,e Digitalized Self-contained Systems have limited applicability for smart energy applications and Open Blockchain Energy (OBE) [ 18] shows a short description of a framework as Distributed and Decentralized. The framework is requiring a utility microgrid aggregator and that application require high throughput and the concept [18] lacks of scalability solution. In our approach we examine how a DLT architecture can be used to distribute the aggregator's role across all devices on a microgrid network. In order to address scalability and different from existing approaches we proposed logical clustering on the DLT-based microgrid.

The third aspect is the energy application. Table 3 lists applications that benefit from recent developments in decentralized and/or distributed computing, and that are crucial for a digital infrastructure that can handle a large portion of DERs. The listed applications (grid monitoring and management, cyberphysical security, and wholesale/P2P trading) are computational intensive, require high throughput, are strictly regulated, and require a scalable solutions. Table 2 elicits the characteristics of value exchanges: \{cyberphysical indistinguishable, immediate, time-bound, objective exchange in the case of grid monitoring and management and cyberphysical security; and \{abstract representation, eventual, time-bound, legal institution $\}$ in the case of energy markets. Consequently we need low latency finality and high throughput, i.e., a Distributed and Centralized Elective system like Hyperledger Fabric [14]. While Hyperledger Fabric is well suited for ensuring legal compliance and for the consortium type networks that characterize grid connected DERs it is communication bound and has failed to scale in past energy trials [11]. Consequently, we developed new consensus protocols and designed on subnetworks and aggregation. To ensure security, integrate the existing solutions that secure data inputs, data operations, and message exchanges between grid entities. As our proposed relies heavily on DERs, there is a need to consider new valuation models and grid services. In the next section we present our approach and to support the approach and the conceptualization and implementation of DLT-based microgrid we present a proof-of-concept implementation of a small DLT-based machine-to-machine and demonstrates that DLT technology can establish small-scale electricity markets.

\section{A DLT-based Architecture for Smart Grid}

Based on the DLT we derive layered architecture components for the efficient operation of DLT-based microgrid energy. A schematic overview of the components making up the microgrid market's framework is given in Fig. 1. 


\subsection{A Layered Architecture with DLT Overlay}

DLT technology can benefit the management of the Smart Grid in that the privacy, transparency and security can be dealt by the DLT network itself. This enables an easy and efficient way to provide transparent and trustworthy services to electricity users and keep the power transmission system secure and efficient. Fig. 1 illustrates the management architecture for Smart Grid based on DLT. It makes full use of the features provided by DLT, and at the same time, uses the current wellaccepted edge and cloud computing to obtain the efficiency and scalability of the whole system.

The architecture consists of four layers. The Grid Infrastructure Layer consists of equipment producing and/or consuming electricity power that needs to be managed and controlled, as well as the devices that measure and control the load of the power system. The Edge Computing Layer performs certain data storage and processing and provides some services and data related to local areas. The Cloud Computing Layer mains the grid level database and polities, and performs data analysis at the whole grid level. The DLT Network Layer is an overlay, consisting of the trustworthy nodes in the infrastructure, edge and cloud computing layer.

3.1.1. Grid Infrastructure Layer (GIL)

As mentioned above, the technical advancements have made it possible for electrical consumers to become also an electrical producers and be deeply involved in the Smart Grid as prosumers. The energy system of the future will be a decentralised system. Thus, the infrastructure layer consists of

Table 2. Categories of the underlying value and solution types with details of suitable and non-suitable uses.

\begin{tabular}{|c|c|c|c|c|}
\hline $\begin{array}{l}\text { Cate } \\
\text { gory }\end{array}$ & Type & Description & Advantages & Disadvantages \\
\hline \multirow{5}{*}{$\begin{array}{l}\text { Value } \\
\text { s } \\
\text { Repr } \\
\text { esent } \\
\text { ation }\end{array}$} & Self-referring & $\begin{array}{l}\text { State updates require only inputs stored on the } \\
\text { blockchain }\end{array}$ & Trustless state updates & Cannot interact with external events \\
\hline & Digital only & $\begin{array}{l}\text { State updates require external inputs about digital } \\
\text { events }\end{array}$ & $\begin{array}{l}\text { Can interact with external digital } \\
\text { events }\end{array}$ & $\begin{array}{l}\text { Cannot interact with non-digital events. } \\
\text { The oracle connectivity problem }\end{array}$ \\
\hline & $\begin{array}{l}\text { Cyber-physical } \\
\text { distinguishable }\end{array}$ & $\begin{array}{l}\text { State updates require external inputs about events } \\
\text { with distinguishable physical components }\end{array}$ & $\begin{array}{l}\text { Can interact with physical events } \\
\text { where the components are } \\
\text { distinguishable and possible to } \\
\text { mirror digitally }\end{array}$ & $\begin{array}{l}\text { Difficult to implement. Difficult to } \\
\text { secure accurate and durable data inputs. } \\
\text { Oracle connectivity problem. }\end{array}$ \\
\hline & $\begin{array}{l}\text { Cyber-physical } \\
\text { indistinguishable }\end{array}$ & $\begin{array}{l}\text { State updates require external inputs about events } \\
\text { where physical components are interchangeable }\end{array}$ & $\begin{array}{l}\text { Same as above but for all physical } \\
\text { events }\end{array}$ & $\begin{array}{l}\text { Same as above but with additional } \\
\text { challenges related to distinguishing }\end{array}$ \\
\hline & $\begin{array}{l}\text { Abstract } \\
\text { representation }\end{array}$ & $\begin{array}{l}\text { State updates require external inputs such as } \\
\text { assurances and trust signals }\end{array}$ & $\begin{array}{l}\text { Easy to use in trusted actor } \\
\text { networks }\end{array}$ & Very easy to cheat. Costly audits \\
\hline \multirow[t]{2}{*}{$\begin{array}{l}\text { Coup } \\
\text { ling }\end{array}$} & Immediate & $\begin{array}{l}\text { The representational layer must accurately } \\
\text { correspond with the physical layer at all times }\end{array}$ & $\begin{array}{l}\text { Absolute finally and no delay } \\
\text { between physical events and digital } \\
\text { representation }\end{array}$ & $\begin{array}{l}\text { Technically very challenging to achieve } \\
\text { in distributed and decentralized networks }\end{array}$ \\
\hline & Eventual & $\begin{array}{l}\text { The representational layer will eventually } \\
\text { correspond to the physical layer }\end{array}$ & $\begin{array}{l}\text { Possible to run on a large number of } \\
\text { resource constrained devices. } \\
\text { Support dynamic sets }\end{array}$ & $\begin{array}{l}\text { Not suitable for delay sensitive } \\
\text { applications requiring absolute finality }\end{array}$ \\
\hline \multirow[t]{2}{*}{$\begin{array}{l}\text { Value } \\
\text { type }\end{array}$} & Derivable & $\begin{array}{l}\text { The value representation is derived by the entire } \\
\text { transaction history }\end{array}$ & Highly auditable & $\begin{array}{l}\text { High storage demands. Only suitable } \\
\text { when transaction dependencies exist }\end{array}$ \\
\hline & Time-bound & $\begin{array}{l}\text { The value representation is only kept for a certain } \\
\text { amount of time and is then pruned }\end{array}$ & Efficient Storage & Timeless audit trails \\
\hline \multirow{4}{*}{$\begin{array}{l}\text { Dispu } \\
\text { te } \\
\text { resol } \\
\text { ution }\end{array}$} & $\begin{array}{l}\text { Objective } \\
\text { exchange } \\
\text { negotiation }\end{array}$ & $\begin{array}{l}\text { Exchanges involve only performances and } \\
\text { payments that are objective, expressible and } \\
\text { formally verifiable }\end{array}$ & $\begin{array}{l}\text { Automation and eliminates human } \\
\text { intervention }\end{array}$ & $\begin{array}{l}\text { Most negotiations have subjective } \\
\text { elements and grey area elements that } \\
\text { cannot be captured }\end{array}$ \\
\hline & $\begin{array}{l}\text { Randomized } \\
\text { quorum }\end{array}$ & $\begin{array}{l}\text { Resolution involves the selection of a quorum of } \\
\text { incentivized nodes who cast votes }\end{array}$ & $\begin{array}{l}\text { Can handle subjective elements and } \\
\text { grey area elements }\end{array}$ & $\begin{array}{l}\text { Ochlocracy since incentives are tied to } \\
\text { voting as the majority votes }\end{array}$ \\
\hline & $\begin{array}{l}\text { Arbitration / } \\
\text { expert input }\end{array}$ & Resolution is based on expert input & $\begin{array}{l}\text { Treatment of subjective and grey } \\
\text { area elements. Efficient resolution } \\
\text { by domain expert }\end{array}$ & $\begin{array}{l}\text { Limited possibility to automate. Actors } \\
\text { can still pursue legal action }\end{array}$ \\
\hline & Legal instruction & Off-chain resolution & $\begin{array}{l}\text { Regulatory compliance across } \\
\text { jurisdictions }\end{array}$ & No automation. Costly and slow \\
\hline
\end{tabular}

equipment producing and/or consuming electricity power, including those installed at users' locations, such as solar panels, smart batteries and deferrable assets. All the equipment must be well managed and controlled in order to maintain the stable of the whole grid system and reduce the waste of the "green" electricity produced by customers.

Moreover, an intelligent meter will be installed at each prosumer (including the institutions and companies). It can measure the amount of energy (e.g, in kilowatt hour) each prosumer has consumed and produced, and can also control the electrical equipment, producing or consuming electricity according to the specified mode. In addition, micro load management devices (M-LMDs) belong also to the infrastructure layer. M-LMDs are dynamic and intelligent circuit breakers controlled by programmed load management parameters. It can send instructions to the meters at each prosumer to control the local equipment. M-LMDs will be installed in the junctions of the low voltage electrical transmission line covering a local area. The M-LMDs communicates each other and with intelligent meters over wireless transmission. M-LMDs are also capable for demand response and fault detection and recovery. Electrical users can download a mobile applications to communicate with intelligent meters and M-LMDs, and visit the DLT network, tracing the usage of the electricity. It can also control electrical equipment through intelligent meters.

\subsubsection{Edge Computing Layer (ECL)}

The Edge Computing Layer is responsible for certain data storage and processing, and providing services by analysing locally obtained data. As shown in Fig. 1, a local grid aggregator (LG-Aggregator) will aggregate data from several M-LMDs and perform certain computations. It will store, process and analyse the data sent from M-LMDs, and send data to the server in the cloud periodically according to the strategy provided by the cloud. In addition, the edge computer maintains also certain dynamic states information of the whole energy grid from the cloud. Since the edge computer is physically close to M-LMDs and customers' equipment where 
Table 3. Applications that benefit from recent developments in decentralized and/or distributed computing

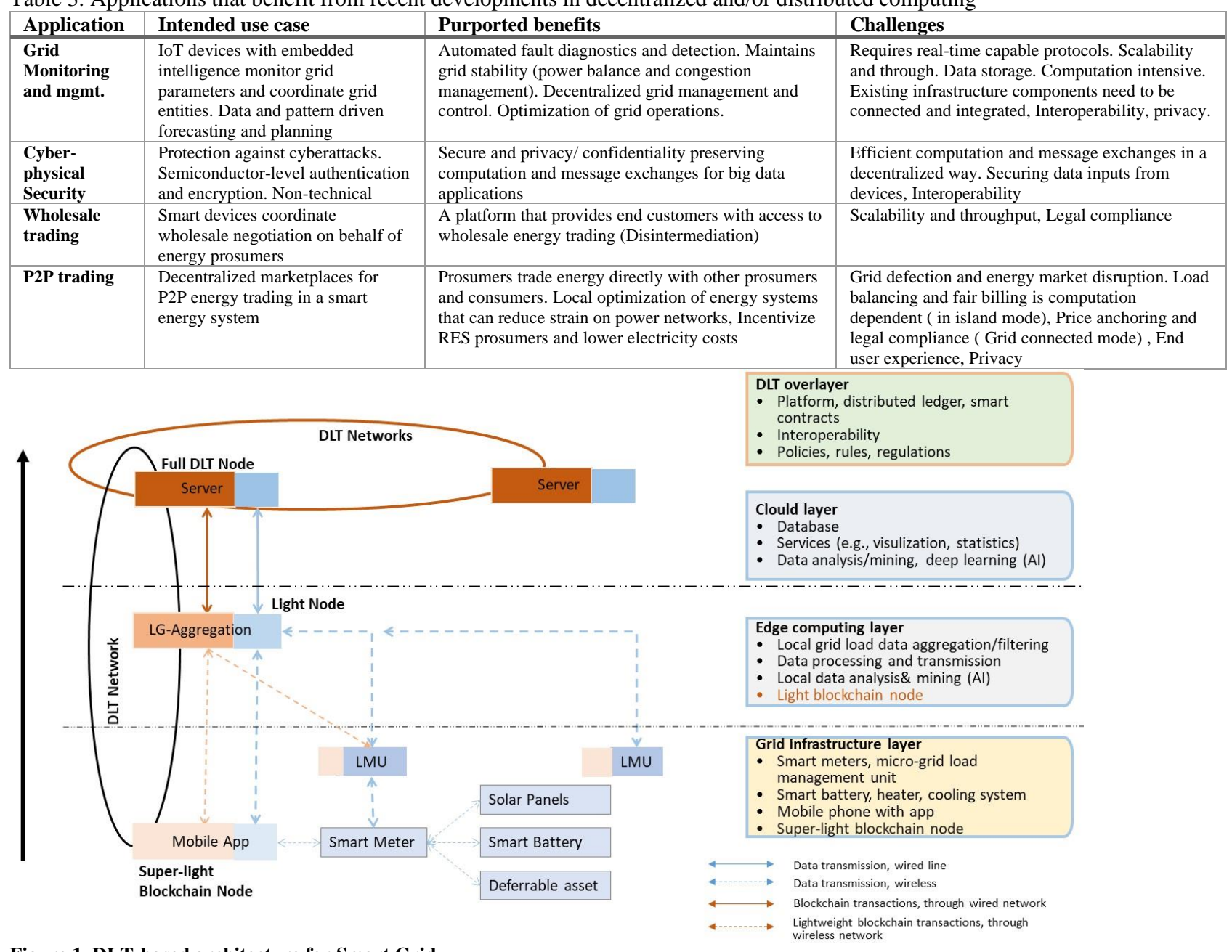

Figure 1. DLT-based architecture for Smart Grid

data are collected, the edge computer can response the MLMDs quickly due to the short data transmission delay, which will control the local equipment with the help of intelligent meters accordingly. Therefore, and data obtained from the grid through cloud, and is responsible for control the stability of the local grid level.

\subsubsection{Cloud Computing Layer (CCL)}

Cloud computing can process data very efficiently due to the high capability of cloud computers and the various information from the whole grid system. As shown in Fig. 1, LGAggregators connect to a server in the cloud. Thus, the server will have the dynamic data of the whole grid. Further performance evaluation of the grid, as well as data mining, deep learning will be done by at the cloud level by using the data from the whole grid. In addition, the whole system and the data will be visualized, which will benefit the analysis and decision of the whole energy management system.

3.1.4 DLT Overlay Layer (DOL)

The blockchain network is an overlay built on top of the GIL, ECL and CCL. It is a virtual network consists of nodes in the GIL, ECL and CCL, which can act as the DLT nodes (in Fig.1, orange colour denotes nodes or transactions belonging to the DLT overlay). Using overlay ensures that the existing data communication protocols, services and data exchanges without privacy-protecting and security requirements will not be affected. Smart contracts are programs executing in DLT driven by events. They work similar to contracts in the real world: when all the prescribed terms are fulfilled, certain actions will be executed. Therefore, by introducing the DLT Overlay, certain secure services related with agreements between grid operators and users can be realized in the form of smart contracts. This can reduce the overhead of time and monetary cost, and can also eliminate the mistakes and misbehaviors from human beings, increasing the reliability of the services. In our architecture, the blocks (ledgers) will store, in a tamper proof manner, the energy production and consumption related data collected from intelligent meters. The self-enforcing smart contracts define programmatically the expected energy flexibility at the level of each producer and consumer, and thus, establish the rules for balancing the energy demand with the energy production at grid level, keeping the grid system stable. Through this way, DLT will provide a trustworthy and transparent means for encouraging green energy usage and reducing energy waste in a flexible and controllable way. For example, since the DLT can trace all the transactions in the network and therefore knows the origin of every unit of electricity, a consumer can choose what type energy he wants to use, e.g., from which generating plants or household he wants to purchase his electricity.

By introducing the DLT overlay, the privacy-sensitive data, such as the value of meters, the type of each user's electrical equipment, and its geographical location, is encrypted and/or replaced by a public key, and will be stored, processed and exchanged through the DLT overlay. In addition, the transactions of each user, i.e., the amount and type of electricity power a user consumed or produced can be well 


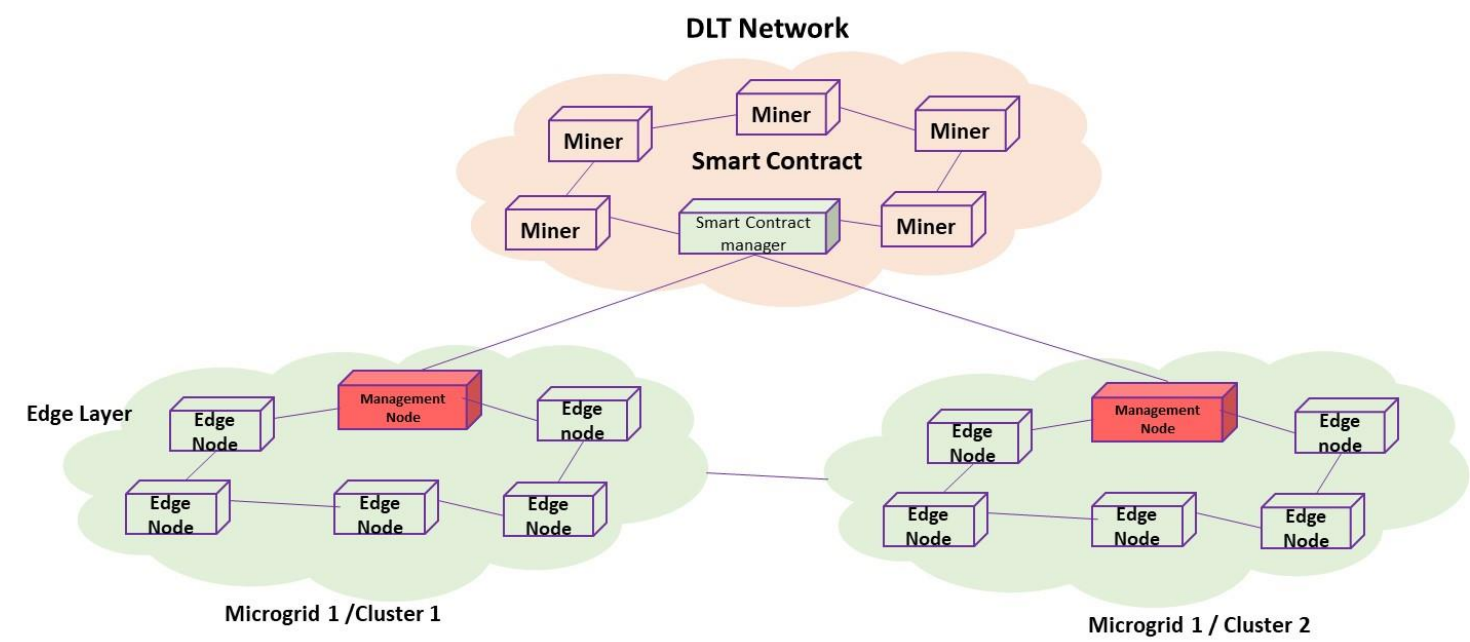

Fig. 2 Distributed architecture DLT-based microgrid

Note that not all the nodes in the DLT overlay have full function of a DLT. Servers at the CCL can maintain a full copy of the blocks and work as miners. Since the DLT nodes can see all the transactions happened in the DLT, only the trustworthy nodes can work as this type of nodes. For example, some of the routers with high computing power in the core network, or servers from the grid operator can be authorized to act as this type of nodes. The LG-aggregator at the ECL are light DLT nodes, it is trustworthy and can only store a copy of the blocks in the local areas. In practice, the definition and size of the area depend on the deployment of the architecture. The users' mobile devices are super-light DLT node in that they can only exchange transactions with the grid, without storing blocks or being as miners.

\section{2 . Dynamic Electricity Price and Grid Stability}

The participant of users' equipment in generating power to the Smart Grid can generally reduce the cost for each customer and is environment friendly. However, this may either cause the whole grid unstable, or potentially waste the electricity produced by each customer due to the limitations of weather and equipment of customers. In order to keep the stability of the Smart Grid, a dynamic electricity price mechanism is used in the architecture. The more each type of electricity is generated to the grid, the lower the price, and vice versa. In addition, each customer can also specify his preference of energy types in his contract (i.e., offline) with the grid management, which will be programmed in the smart contract after the user has been registered in the DLT. Based on electricity price and users' preference, a smart contract can be created between each user and the Smart Grid operator.

Thus, being a super-light DLT node, each user maintains an "energy wallet", and deals with the Smart Grid operator by exchanging transactions on the DLT and executing the smart contract in the DLT automatically. In this way, the information of each unit $(\mathrm{kwh})$ of electricity consumed or produced by a user is transparent to users - every unit of electricity can be traced down to where it is produced - whether it is renewable energy or whether it originates from a nuclear power plant for instance. The electricity customers can choose from which generation plant they want to be supplied. Customer preferences are noted in a smart contract and thereafter executed on automatically to guarantee supply with electrical energy from the preferred energy generation plant. The delivery is verified by transferring the coded kilowatt hour to the customer's "energy wallet". For example, when a neighbour's solar panels make excess energy, the smart contract automatically redistribute it to a customer nearby who is willing to buy local and clean energy generated from the sun. This enables the buying and selling of the renewable energy generated in the local grids and among neighbouring customer groups.

\subsection{Storage and Load Aggregation}

In practice, the dynamic price and grid stability can also be achieved through the smart storage and load aggregation. In time of high generation and thus low prices, individual smart batteries can store energy motivated by the payments (i.e., gains) over the DLT in their private prosumer "energy wallet". Therefore, the load on the grid will be reduced. Similarly, in time of high demand and high prices, electricity will be supplied from the individual batteries. Through the flexible prices and prosumer payments based on pre-programmed user preferences set in smart contracts, the grid will be automatically stabilized. The battery solution is intended for multi-family houses with or without a photovoltaic system and shall communicate seamlessly with smart energy meters in the same low voltage system. In addition, the stability can also be achieved by controlling the usage of deferrable assets through the dynamic price. Deferrable assets, such as water heaters or cooling systems, can be switched on when the overall demand is low and can be switched off when the overall electricity demand is high. By controlling and aggregating different types of electrical equipment dynamically with the help of dynamic electricity prize and smart contract, a balance in the demand and supply can be achieved and the load stability of the Smart Grid can be maintained.

\subsection{DLT for Clustered Local Microgrid}

As shown in Fig. 2 DLT-based microgrid can make decision based on the defined of local market participants and the form of energy traded will be defined.

To realize the above architecture following increase of the security of energy supply or the integration of local renewable generation into the energy supply system must be consider scalability [19], [20] and [21]. In order to address scalability and different from existing approaches by propose logical 


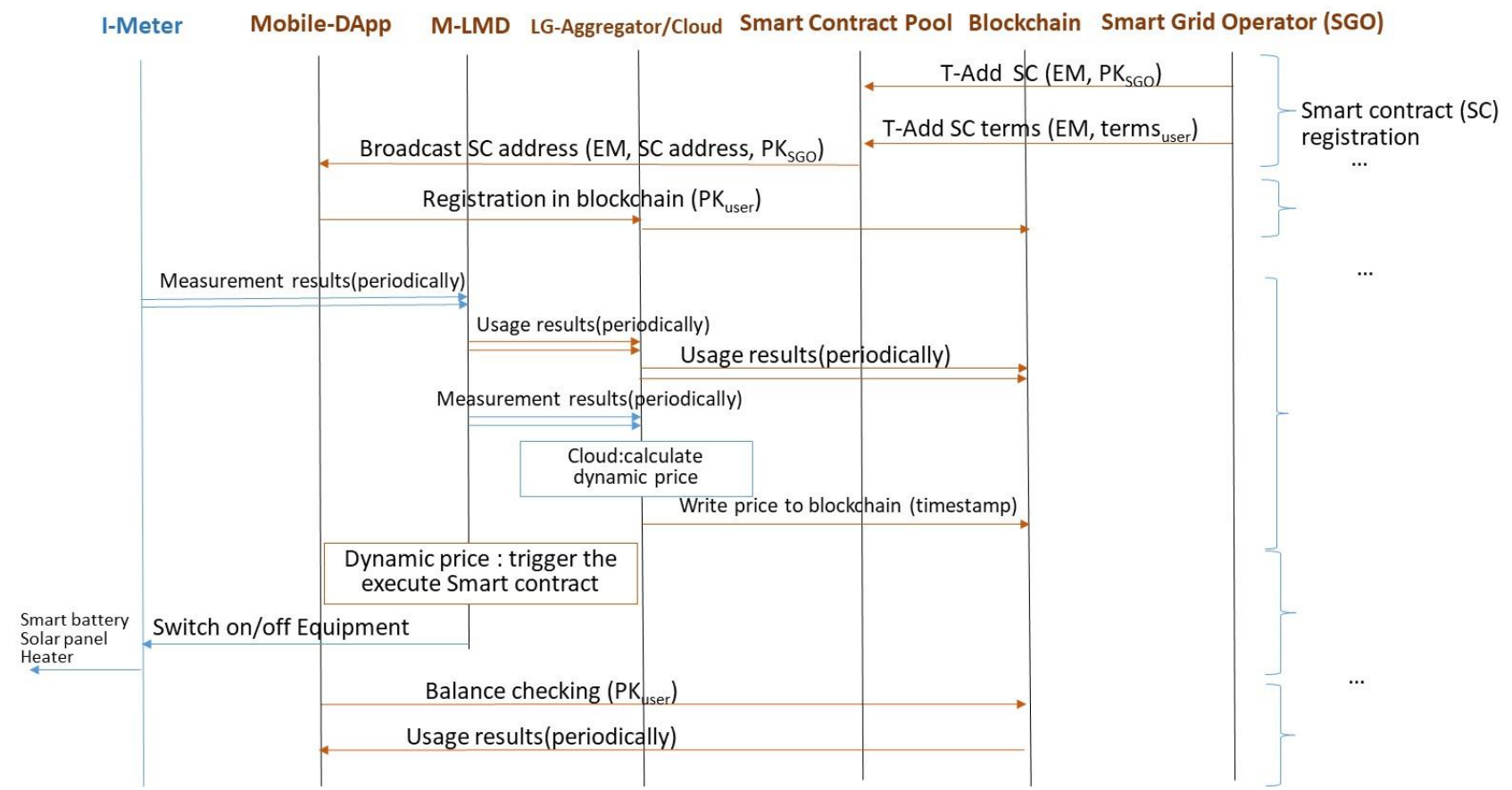

Fig. 3 Electricity usage control procedure based on the dynamic electricity price and smart contract

clustering on the DLT-based microgrid shown in Fig. 2. Our approach limit transaction and forwarding and do not allow any inconsistency in the smart contract changes. A cluster of them needs to have ability to trading energy amongst each other. Each cluster will get market access and it should be given access to the communities residents or similar defined clusters of market participants.

\subsection{Prototype Implementation}

We have implemented a simple prototype of the architecture based on Quarkchain [22] platform. A server is configured as a full blockchain node at the cloud layer and another server is configured as blockchain node but without miner function, acting as a LG-aggregator. A DApp (distributed application) software is developed for mobile phones, allowing users to join the blockchain. Through the DApp, users can check the balance of their "energy wallet" after selling his power to the grid or buying power from the grid. User can also trace their usage of the energy by checking all the exchanged transactions with the Smart Grid. Fig. 3 illustrates the electricity usage control procedure for prosumers based on the dynamic electricity price and smart contract in the prototype. Note that in Fig. 3, orange lines denotes the transactions within DLT overlay, while the blue lines denotes the data exchanges between the entities:

a) First, the Smart Grid operator, as the manager of the grid, register the smart contract (i.e., EM, electricity management) in the DLT network, containing the usage preferences of each user.

b) A user registers in the DLT, and becomes a user in the grid system. His electricity usage preferences will be created as an instance of the smart contract EM.

c) M-LMD collects the values periodically from the intelligent meters at each user, and send them to the LG-Aggregator, which will be recorded in the DLT.

d) M-LMD will also measure the load of the micro area, and send them to LG-Aggregator. LG-Aggregator will store the data for later use (i.e., further analyses and mining locally), and send the data to the cloud server. After getting data from relevant LG-Aggregators, the dynamic electricity price will be calculated and write into the DLT. e) The value of the dynamic price trigger the execution of the smart contract. According to the load of the grid and the user's preference parameter, control information will be sent to Imeter, which will further control the various equipment in the user.

\section{Conclusion}

In this paper, we propose a DLT-based architecture for energy grid with development of existing solution concepts by implementing scalability solutions. To this end, we derive energy market components as a framework for building efficient microgrid. Then, we discuss the microgrid as a case study of such a market according to the required components within energy production, transmission, and distribution; distributed ledger platform operations, IoT device manufacturing, software development; and research in IoT, edge and cloud computing, and energy systems. A DLT overlay is formed on top of the DLT-based microgrid energy markets to locally trade distributed generation infrastructure and the edge and cloud computing nodes. It uses the dynamic price and smart contract to keep the stability of the Smart Grid, at the same time, users can trace the detail of their energy production and consumption. A simple prototype has been implemented to prove the proposed architecture.

For the moment we use only a very simple method to calculate the dynamic price in the smart contract. We are now working on a new algorithm to define the price of the electricity by analyzing the load data of various electricity types. In addition, we will also implement the M-LMD by improving the current product and realize the architecture in field trial.

\section{References}

[1] U.S. Department of Energy (2015). Chapter III: Modernizing the electricity grid. QER Report: Energy Transmission, Storage, and Distribution Infrastructure: 133. 
[2] Mengelkamp E, Notheisen B, Beer C. Blockchain-based smart grid: towards sustainable local energy markets. Computer Science - Research and Development, 2018; 33(1-2): 207-214. https://doi.org/10.1007/s00450-017$\underline{0360-9}$

[3] Weyman-Jones, Thomas, Jùlia Mendonça Boucinha, and Catarina Feteira Inàcio. (2015) "Measuring electric energy efficiency in Portuguese households: a tool for energy policy." Management of Environmental Quality: An International Journal 26 (3): 407-422. https://doi.org/10.1108/MEQ-03-2014-0035

[4] T. Aste, P. Tasca, and T. D. Matteo. (2017) "Blockchain technologies: the foreseeable impact on society and industry." Computer, vol. 50, no. 9, pp.18-28. https://doi.org/10.1109/MC.2017.3571064

[5] F. Hawlitschek, B. Notheisen, and T. Teubner. (2018) "The limits of trust-free systems: a literature review on blockchain technology and trust in the sharing economy." Electron. Commer. Res. Appl. 2018, 29, 50-63. https://doi.org/10.1016/j.elerap.2018.03.005

[6] Jimeno J, Anduaga J, Oyarzabal J, de Muro AG. Architecture of a microgrid energy management system. Euro Trans Electr Power 2011;21(2):1142-58. https://doi.org/10.1002/etep.443

[7] R. Guo, H. Shi, Q. Zhao, and D. Zheng. (2018) "Secure attribute-based signature scheme with multiple authorities for blockchain in electronic health records systems," IEEE Access, vol. 6, pp. 11 676-11 686. https://doi.org/10.1109/ACCESS.2018.2801266

[8] J. Gao, K. O. Asamoah, E. B. Sifah, A. Smahi, et al. (2018) "GridMonitoring: Secured Sovereign Blockchain Based Monitoring on Smart Grid," IEEE Access, 2018. DOI: 10.1109/ACCESS.2018.2806303. https://doi.org/10.1109/ACCESS.2018.2806303

[9] Andoni, M., Robu, V., Flynn, D., Abram, S., Geach, D., Jenkins, D., ... \& Peacock, A. (2019). Blockchain technology in the energy sector: A systematic review of challenges and opportunities. Renewable and Sustainable Energy Reviews, 100, 143-174. https://doi.org/10.1016/j.rser.2018.10.014

[10] Ahl, A., Yarime, M., Tanaka, K., \& Sagawa, D. (2019). Review of blockchain-based distributed energy: Implications for institutional development. Renewable and Sustainable Energy Reviews, 107, 200-211. https://doi.org/10.1016/j.rser.2019.03.002

[11] Green, J., \& Newman, P. (2017). Citizen utilities: The emerging power paradigm. Energy Policy, 105, 283-293. https://doi.org/10.1016/j.enpol.2017.02.004

[12] https://arena.gov.au/assets/2017/10/Final-Report-MHCAGL-IBM-P2P-DLT.pdf

[13] Hassan, N. U., Yuen, C., \& Niyato, D. (2019). Blockchain Technologies for Smart Energy Systems: Fundamentals, Challenges and Solutions. arXiv preprint arXiv:1909.02914.

[14] Hyperledger Fabric is a Distributed ledger software, Accessed on Feb. 10 2020, [Online], Available: https://www.hyperledger.org/projects/fabric
[15] Ren, Z., Cong, K., Pouwelse, J., \& Erkin, Z. (2017). Implicit consensus: Blockchain with unbounded throughput. arXiv preprint arXiv:1705.11046.

[16] Ethereum is a global, open-source DLT based platform for decentralized applications, Accessed on Feb. 10 2020, [Online], Available: https://ethereum.org/

[17] Conti, M., Kumar, E. S., Lal, C., \& Ruj, S. (2018). A survey on security and privacy issues of bitcoin. IEEE Communications Surveys \& Tutorials, 20(4), 3416-3452. https://doi.org/10.1109/COMST.2018.2842460

[ 18] C. Lima, "Towards an Open DLT Blockchain Energy Standards for Decentralized Grid Applications", Accessed on Feb. 10 2020, [Online], Available: https://www.standardsuniversity.org/e-magazine/may2019-volume-9-issue-1-blockchain-standards/towards-anopen-dlt-blockchain-energy-standards-for-decentralizedgrid-applications/.

[19] Rahmani, R., Li, Y. and Kanter, T.,. A Scalable Distriubuted Ledger for Internet of Things based on Edge Computing. Accessed on Feb. 10 2020, [Online], Available: In: http://ccit.theired.org/. IRED. pp.4145.https://www.seekdl.org/conferences/paper/details/9862. html'

[20] Pascual J, Barricarte J, Sanchis P, Marroyo L. Energy management strategy for a renewable-based residential microgrid with generation and demand forecasting. Appl Energy 2015;158:12-25 https://doi.org/10.1016/j.apenergy.2015.08.040

[21] Rahmani, R. and Kanter, T.,. Layering the Internet-ofThings with Multicasting in Flow-sensors for Internet-ofservices. International Journal of Multimedia and Ubiquitous Engineering, 10(12), Science \& Engineering Research Support Center. https://doi.org/10.14257/ijmue.2015.10.12.05

[22] QuarkChain, A high Capacity P2P and DLT based Transactional System, Accessed on Feb. 10 2020, [Online], Available: , https://quarkchain.io/ 